\title{
ESTRUTURA E EVOLUÇÃO DA FAMILIA ROMANA
}

Prof. ELPIDIO FERREIRA PAES *

Um estudo embora resumido de três vocábuios mostra os aspectos fundamentais da organização familial romana.

\section{A GENS}

1. - A família romana, durante séculos, apresenta organização patriarcal. Significa isso que a família era, essencialmente, um grupo de pessoas subordinadas à autoridade de um chefe. Esse grupo de pessoas se dizia "gens" e (como lembra Monier) tinha um sentido político anterior à cidade. Era a predominância da vontade masculina sôbre a feminina, a supremacia da "condictio maris" sôbre a "condictio feminae"... Lewis e Short ligam êsse têrmo à raiz "gen", que indica os indivíduos ligados pelo nascimento ou descendência; e definem o vocábulo como "raca ou clan abrangendo várias famílias unidas por um nome comum e determinados ritos religiosos", pois, em verdade, o chefe da gens era também o chefe do culto doméstico. E apresentam o exemplo formulado por Salústio: "Sulla gentis patriciae nobilis fuit, familia pro pe jam exstincta majorum ignavia". (J. 95, 3). E Cícero, referin do o crime do jovem Tarquínio contra Lucrécia, informa que Bruto "exulem gentem Tarquiniorum esse jussit". (Rep. II.25.45).

* Catedrático de Direito Romano. 
2. - Os membros de uma "gens" se diziam "gentiles", e essa qualidade de "gentiles" se revelava pela comunidade de nome e de origem, como informa Festo: "Gentilis dicitur et ex eodem genere ortus, et is qui simili nomine appellatur, ut ait Cincius: GENTILES MIHI SUNT QUI MEO NOMINE APPELLANTUR". Cícero procura tornar mais precisa a definição especificando em 'Tópica (6.29): "Itemque ut illud: GENTILES sunt inter se qui eodem nomine sunt. Non est satis. Qui ab ingenuis oriundi sunt. $\mathrm{Ne}$ id quidem satis est. Quorum maiorum nemo servitutem servivit. Abest etiam nunc. Qui capite non sunt deminuti. Hoc fortasse satis est." Mas verificamos que o próprio Cícero não revela segurança na conceituação, posto que usa a palavra "fortasse" . . Entretanto vemos que a unidade de nome e de origem são elementos característicos da GENS. Ainda ao tempo de Augusto, embora houvesse evoluido grandemente a organização familial, o vocábulo era usado no sentido original, como se pode ver, p.e., em Ovídio, Pont. 4.6.8: "Certus eras pro me, Fabiae laus, Maxime, GENTIS" ...

Nem se deve esquecer que "gens" no plural indicava os povos em geral, donde a expressão "JUS GENTIUM", que as Institutas de Justiniano (1.2.2) definem: "JUS GENTIUM omni humani generi commune est; nam, usu exigente et humanis necessitaüibus, gentes humanae quaedam sibi constituerunt..."

\section{PATER}

3. - Já vimos que a "direção", a "regência" da "gens" cabia a um homem que se tornava responsável por sua segurança, manutenção, desenvolvimento. A êsse homem dava-se o título de "pater".

Ora para que essa proteção fôsse realmente eficaz seria mister que se conferisse ao pater ampla autoridade sôbre a "gens", i.é sôbre seus subordinados e respectivos bens (res), portanto sôbre a "domus". Por isso, informa Ulpiano, no Digesto (50.16.195, 2), que "pater familias appellatur qui in domo dominium habet"; e esclarece que lhe cabe êsse título "quamvis filium non habeat". Isso mostra que a paternidade, em sentido técnico-jurídico, se afasta do sentido natural. Os bens submetidos à autoridade do "pater" constituiam o "patrimonium".

4. - Os elementos masculinos de uma gens se diziam patricii (derivado de pater). Outrossim por terem resultado de uma gens e serem livres, eram igualmente denominados ingenui (in- gen-ui), segundo afirma Festo: "patricios eos appellari solitos qui nunc ingenui vocentur".

Por conseguinte, "pater" era sempre o "superior" de uma comunidade patricia. Competia, outrossim, aos patrícios o exercício de certos encargos na comunidade política, o que significa a defesa, o desenvolvimento da comunidade. Tais encargos se diziam "honores", pois era alta distinção poder exercê-los. Era o que ocorria, p.e., com o "senatus" (conselho dos velhos), cujos membros, durante muito tempo, foram escolhidos entre os patrícios. Daí a denominação que se lhe dava: patres, e, mais tarde, patres conscripti.

Eis outro nexo entre o fato político e o fato doméstico.

Nem se confunda o "pater familias" romano com o "pai-defamília" moderno; as atribuições e a autoridade de um e outro diferem...

5. - Assim como o "magistratus" exercia sua "potestas" sôbre os cidadãos, o "pater familias" desempenhava sua "potestas" sôbre os elementos da "gens". Bastam alguns textos para que tenhamos uma idéia do poder amplo (ou talvez melhor "imenso") do "pater". A Lei das Doze Táboas (IV) afirma que a "lex dederat patri in filium vitae necisque potestatem". Podia ainda o pa vender o filho até três vêzes, porém na tercera perdia a "patria potestas": "Si pater filium ter venum duit filius a patre liber esto". (Tab. IV).

Não se deverá, contudo, deduzir daí que os pais romanos eram carrascos profissionais, usando êsses direitos "terríveis" indiscriminadamente. Ainda mais, êsse "poder agressivo" cedo foi desaparecendo e no fim da República era apenas uma fraca recordação como o ccnceito de "gens"... O pater era equiparado a um magistrado e para ditar sua decisão no caso da integridade do "filius" normalmente recorria ao "consilium propinquorum".

6. - A mulher casada "cum manu" (i.é sob a "potestas" do marido) chamava-se "mater familias". Aulo Gélio (18.6.9) afirma "matrem familias appellatam esse eam solam quae in mariti manu... esset". A verdade é que mais tarde também a casada "sine manu" recebia o título de "mater familias".

Mas ainda que integral ou relativamente subordinada ao marido, a "mater familias" era profundamente respeitada na vida social.

E Aulo Gélio (ib.) afirma ainda "matronam dictam esse proprie, quae in matrimonium cum viro convenisset, quoad in eo matrimonio maneret". O casamento, pois, dignificava a mulher, dando-lhe um tom de autoridade no lar. $E$ isso deveria satisfazer a dama romana dos primeiros tempos. Exemplo eloquente da "matro- 
trona romana" foi Cornélia, mãe de Tibério e Caio Graco, a qual, perdendo o marido, soube educar seus filhos com dignidade e inteligência.

\section{FAMíliA}

7. - Esta palavra passou por evolução mais ou menos longa até fixar-se como conceito definido.

A palavra familia se relaciona com "famulus". Já Festo afirmava que "famuli origo ab Oscis dependet, apud quos servus famel nominabatur, unde et familia vocata". Isidoro (Etym., 9.4.43), comparando os dois vocábulos - "famulus" e "servus" - afirma que "famuli sunt ex propria familia orti. Servi . . . quod hi, qui jure belli possint occidi a victoribus, cum servabantur, servi fiebant, a servando scilicet servi appellati". Entretanto, Ernout e Meillet não concordam com esta última opinião, citando o verso de Vergílio (En., III, 329): "Me famulam famuloque transmisit habendam". Para os dois grandes humanistas não ocorre, entre famulus e servus a distinção estabelecida por Isidoro, e acreditam que "servus" indica, não "o prisioneiro salvo da morte", mas a condição jurídica do escravo, enquanto "famulus" refere-se ao escravo encarregado de uma função especial. Pode ser razoável tal opinião, mas os próprios filólogos reconhecem que não há elementos suficientes para decidir tal assertiva.

Outra opinião interessante é a de Bréal, segundo o qual famulus significaria "o habitante da casa". Porém faltam elementos mais seguros para confirmá-lo.

8. - Quanto a familia, segundo Ernout e Meillet, deve ter designado, inicialmente, o conjunto dos escravos que viviam sob um mesmo teto, em oposição a "gens". A expressão "familia pecuniaque" designava a riqueza do "pater" (res familiares, patrimonium).

Catão (R.R., V) aconselha "litibus familiae supersedat". Mas também em Catão se encontra a palavra indicando um grupo gentilício, ligando-se à própria religião: "Pater familias ubi ad villam venit, ub larem familiarem salutavit... fundum circumeat...". (II)

Mas a verdade é que familia terminou por indicar um conjunto de pessoas sujeitas à autoridade do "pater familias":

1) a mulher casada;

2) os filhos e filhos dos filhos do "pater familias", desde que procreados em justum matrimonium e respectivas espôsas;
3) as pessoas adotadas, e depois os filhos extra-matrimoniais legitimados

4) as pessoas livres que estivessem para com o pater em relação in causa mancipi.

9. - Pouco a pouco se foi modificando êsse regime baseado no poder de um homem no sentido integral. Aquela família considerada como unidade política e econômica, relacionada pelo sistema da agnatio, foi sendo substituida pela família fundada na cognatio. Aqueles privilégios paternos foram sendo derrubados: Diocleciano proibiu a venda dos filhos; a situação da mulher casada já não se conservava "in manu mariti". O matrimônio "sine manu" generalizou-se a partir do primeiro século do Império. Augusto, no início do Império, permitiu que o filius familias dispusesse do pecúlio castrense. Com a restrição à "vontade paterna", desapareceu o direito de expor o filho recém-nascido.

Em caso de má conduta do pai, a lei concedia à mãe a guarda dos filhos.

Todos os ascendentes maternos têm direito ao respeito de seus descendentes: obsequium e reverentia.

Para maior segurança contra qualquer excesso de autoridade paterna, os imperadores permitiram às pessoas in potestate solicitar a proteção do magistrado pela cagnitio extra ondinem; e a decisão do caso poderia ir até a emancipação do interessado, o que extinguia o pátrio poder. $\mathrm{O}$ que se permitia modica castigatio.

10. - Por outro lado, havia casos em que poderia extinguirse a patria potestas: pela morte do pater, ou ainda pela sua perda de liberdade ou de cidadania; pela perda de liberdade ou de cidadania do filho; por emancipação ou pela adoção do filho por outra pessoa; pelo exercício de um consulado ou de uma prefeitura.

O pater podia sempre locar os serviços de pessoa livre que estivesse in potestate sua; entretanto, o credor que conscientemente recebesse em penhor um filius familias podia ser punido com a deportação.

Finalmente, não podia o pater casar os filhos contra a vontade dêstes e a Lex Julia, no início do Império, permitira ao magistrado interferir quando um pai se opunha ao casamento de uma filha sem um motivo legítimo.

Os juristas do Alto Império admitiam que o "filius familias" tinha personalidade distinta da do "pater familias" e que, portanto "promittendo patrem civiliter non obligat, sed se obrigat". (D.44. 7.39). E o próprio Gáio já advertia que o "filius familias ex omnibus causis tamquam pater familias obligatur..." e precisamente por isso poder-se-ia agir contra êle "tamquam cum patre familias". 
Acrescentava Ulpiano que se um "filius familias" tivesse um pecúlio e alguém quisesse acioná-lo "duos habet debitores, filium in solidum et patrem duntaxat de peculio".

Tudo isso vem demonstrar que pouco a pouco se foi apagando o poder absoluto do "pater", que deixou de ser o "dominus gentis" para se tornar (pelo menos teòricamente) o "patronus liberum", transformando a paternidade numa instituição puramente familiar, rigidamente regulada pelo Estado.

11. - Em face dessa evolução na estrutura familial, é fácil compreender que as relações de parentesco assumem aspectos diversos, predominando primeiro a "agnatio", depois a "cognatio".

Muito mais se poderia dizer para mostrar a riqueza da polissemia jurídica romana, a qual, acompanhando a evolução dos institutos, determina por vêzes a predominância de certos têrmos. $\mathrm{O}$ que ficou dito, entretanto, parece-nos suficiente a oferecer uma pequena idéia do fato.

\section{DELINQUUENCIA POLÍTICA E TERRORISMO}

(Alguns aspectos da dogmática penal)

PROF. JOSÉ SALGADO MARTINS (*)

Em diferentes regiões áo mundo civilizado, os atentados terroristas aparecem com tal freqüência e se revestem de tal crueldade que fazem pensar na revivescência de formas criminais contemporâneas da idade da caverna e que dois milênios de civilização já deveriam haver para sempre sepultado. Parece que volvemos, assim, ao período anterior ao próprio talião, onde, a despeito da vingança privada, já brilhava um vislumbre de justiça, na retribuição do mal pelo mal: ôlho por ôlho; dente por dente.

Agora, as vítimas são, por vêzes, inteiramente inocentes, não havendo delas partido qualquer ato ou gesto que tivesse a mais remota relação com o crime, a cuja fúria são sacrificadas. Os criminosos as escolhem, quase ao acaso, para, nelas, cevar o seu ódio a sua crueldade. Tomam-nas, às vêzes, como símbolos de uma ordem política ou social que querem destruir pela violência. Outras vêzes, vingam-se nas vítimas das frustrações e dos desajustamentos que a vida lhes causou, por motivo de deficiências individuais ou da ideologia malsã que esposaram.

Essa forma de criminalidade, de certo modo, inusitada, está a exigir do atual pensamento jurídico a reformulacão das normas princípios de direito, no sentido de diferençá-la da denominada criminalidade política que a filosofia do liberalismo cercara de uma auréola de simpatia e benevolência.

(*) Catedrático de Direito Penal, Vice-Diretor da Faculdade de Direito de Pôrto Alegre, UFRGS. 